\title{
Quality of life in a randomized phase II study to determine the optimal dose of 3-week cycle nab-paclitaxel in patients with metastatic breast cancer
}

\author{
Naruto Taira ${ }^{1}$ (1) Kosuke Kashiwabara ${ }^{2} \cdot$ Junji Tsurutani $^{3} \cdot$ Masahiro Kitada $^{4} \cdot$ Masato Takahashi $^{5} \cdot$ Hiroaki Kato $^{6}$. \\ Yuichiro Kikawa ${ }^{7}$. Eiko Sakata ${ }^{8}$. Yoichi Naito ${ }^{9}$. Yoshie Hasegawa ${ }^{10}$. Tsuyoshi Saito $^{11}$. Tsutomu Iwasa $^{12}$. \\ Tsutomu Takashima ${ }^{13}$. Tomohiko Aihara ${ }^{14}$. Hirofumi Mukai ${ }^{9}$. Fumikata Hara ${ }^{15}$
}

Received: 5 June 2021 / Accepted: 25 August 2021 / Published online: 7 September 2021

(c) The Japanese Breast Cancer Society 2021, corrected publication 2021

\begin{abstract}
Background To report our findings on quality of life $(\mathrm{QoL})$ in a randomized phase II study to determine the optimal dose of 3-week cycle nab-paclitaxel (q3w nab-PTX) in patients with metastatic breast cancer (MBC).

Methods Patients with HER2-negative MBC were randomly assigned to three different doses of q3w nab-PTX (SD $260 \mathrm{mg}$ ) $\mathrm{m}^{2}$ vs. MD: $220 \mathrm{mg} / \mathrm{m}^{2}$ vs. LD $180 \mathrm{mg} / \mathrm{m}^{2}$ ). QoL was assessed at baseline and during the second, fourth and sixth courses of treatment using the Functional Assessment of Cancer Therapy-Taxane (FACT-Taxane), Cancer Fatigue Scale (CFS) and EuroQol 5-Dimension (EQ-5D). Comparisons were performed with mixed-model repeated measures (MMRM).

Results A total of 141 patients were enrolled in the parent study, and 136 (96\%) (44, 45 and 47 in the SD, MD, and LD groups) were included in the analysis. MMRM analysis showed that the difference from the baseline FACT-Taxane trial outcome index at MD and LD were significantly higher than that at SD (MD vs. SD $P<0.001$, LD vs. SD $P<0.001$ ). Differences from baseline for FACT-Taxane total, physical and emotional well-being, and taxane subscale scores at MD and LD were also higher than at SD. The difference from baseline for the CFS score at LD was lower than at $\mathrm{SD}(P=0.013)$ and those for EQ-5D utility scores at MD and LD were higher than at SD (MD vs. SD $P=0.011$, LD vs. SD $P<0.001$ ).

Conclusion QoL of patients treated with 220 or $180 \mathrm{mg} / \mathrm{m}^{2}$ of q3w nab-PTX was significantly better than that of patients treated with $260 \mathrm{mg} / \mathrm{m}^{2}$.

Trial registration The protocol was registered at the website of the University Hospital Medical Information Network (UMIN), Japan (protocol ID: UMIN000015516), on 01/11/2014. Details are available at the following address: https:// upload.umin.ac.jp/cgi-open-bin/ctr_e/ctr_view.cgi?recptno=R000017916
\end{abstract}

Keywords Metastatic breast cancer $\cdot$ Chemotherapy $\cdot$ Nab-paclitaxel $\cdot$ QoL $\cdot$ CIPN $\cdot$ Fatigue

$\begin{array}{llll}\begin{array}{l}\text { Abbreviations } \\ \text { QoL }\end{array} & \text { Quality of life } & \text { UMIN } & \text { University Hospital Medical Information } \\ \text { q3w nab-PTX } & \text { 3-Week cycle nab-paclitaxel } & \text { PTX } & \text { Network } \\ \text { MBC } & \text { Metastatic breast cancer } & \text { so-PTX } & \text { Solvent-based PTX } \\ \text { FACT-Taxane } & \text { Functional Assessment of Cancer } & \text { q3w } & \text { Every 3 weeks } \\ & \text { Therapy-Taxane } & \text { RR } & \text { Response rate } \\ \text { CFS } & \text { Cancer fatigue scale } & \text { PFS } & \text { Progression-free survival } \\ \text { EQ-5D } & \text { EuroQol 5-dimension } & \text { CIPN } & \text { Chemotherapy-induced peripheral } \\ \text { MMRM } & \text { Mixed-model repeated measures } & & \text { neuropathy } \\ & & \text { HER2 } & \text { Human epidermal growth factor receptor } \\ & & & \text { type2 } \\ & & \text { HR } & \text { Hazard ratio } \\ & & \text { RCT } & \text { Randomized controlled trial } \\ \text { Naruto Taira } & \text { PS } & \text { Performance status }\end{array}$




$\begin{array}{ll}\text { MD } & \text { Medium dose } \\ \text { LD } & \text { Low dose } \\ \text { PWB } & \text { Physical well-being } \\ \text { SFWB } & \text { Social and family well-being } \\ \text { EWB } & \text { Emotional well-being } \\ \text { FWB } & \text { Functional well-being } \\ \text { TOI } & \text { Trial outcome index } \\ \text { 95\% CI } & 95 \% \text { Confidence interval } \\ \text { BMIs } & \text { Body mass indexes } \\ \text { PROs } & \text { Patients reported outcomes }\end{array}$

\section{Background}

Nab-paclitaxel (PTX) is a chemotherapeutic agent for metastatic breast cancer that is administered as a nanoparticulate preparation of PTX bound to human serum albumin. Unlike conventional, solvent-based PTX (so-PTX), polyoxyethylene castor oil or absolute ethanol are not used as a solvent. For this reason, pre-medication with steroid hormones is not needed and a high dose of PTX can be administered in a short time. In patients with metastatic breast cancer, nab-PTX $260 \mathrm{mg} / \mathrm{m}^{2}$ every 3 weeks (q3w) was found to be superior for response rate (RR) and progression-free survival (PFS) compared to $\mathrm{q} 3 \mathrm{w}$ so-PTX $175 \mathrm{mg} / \mathrm{m}^{2}$ [1]. However, in the nab-PTX group, the dose of PTX was approximately 1.5 times higher and the frequency of chemotherapy-induced peripheral neuropathy (CIPN) was significantly higher.

In Japan, nab-PTX was approved in 2010 for treatment of metastatic breast cancer. The recommended dosage of nabPTX by the Pharmaceuticals and Medical Devices Agency is $260 \mathrm{mg} / \mathrm{m}^{2}$ intravenously over 30 min every 3 weeks for metastatic breast cancer. However, a survey on actual use started after release of nab-PTX found that about one-third of cases were treated with a reduced initial dose [2]. In addition, about $30 \%$ of cases that started with the standard dose required dose reduction, mainly due to myelosuppression and CIPN. In particular, the rate of CIPN of Grade $\geq 2$ was as high as about $40 \%$. Based on these real-world findings, the current standard dose of nab-PTX is highly toxic and may be problematic over time. Thus, the current study was planned to investigate the optimal dose of nab-PTX.

This study compared three different doses of q3w nabPTX (SD $260 \mathrm{mg} / \mathrm{m}^{2}$ vs. MD $220 \mathrm{mg} / \mathrm{m}^{2}$ vs. LD $180 \mathrm{mg} /$ $\mathrm{m}^{2}$ ) in patients with human epidermal growth factor receptor type2 (HER2) negative metastatic breast cancer [3]. The primary endpoint was PFS. Grade 3/4 neuropathy rates at the three doses were estimated by logistic regression. The optimal dose was defined by 2-step selection. First, if the hazard ratio (HR) for PFS was $<0.75$ or $>1.33$, the inferior dose was dropped. Then, if the estimated incidence rate of grade $3 / 4$ neuropathy was $>10 \%$, the other dose was dropped. Primary analysis showed that low-dose nab-PTX at
$180 \mathrm{mg} / \mathrm{m}^{2} \mathrm{q} 3 \mathrm{w}$ may be the optimal therapy with meaningful efficacy and favorable toxicity in patients with metastatic breast cancer [4].

In general, the frequency and severity of adverse events caused by chemotherapy are dose-dependent, so a potential benefit of using low-dose nab-PTX is reduction of adverse events. The frequency or severity of CIPN is likely to be reduced with a low-dose nab-PTX regimen, and this dose may also reduce symptoms such as fatigue caused by cancer chemotherapy. Based on the hypothesis that low-dose nabPTX treatment will result in better quality of life $(\mathrm{QoL})$ than standard dose nab-PTX, the purpose of this QoL substudy is to show the superiority of low-dose PTX in terms of QoL.

\section{Methods}

\section{Study design}

This study is a multicenter, open-label, phase 2 randomized controlled trial (RCT) conducted in Japan. Details of study protocols have been reported elsewhere [3]. Briefly, the inclusion criteria were histologically diagnosed invasive breast cancer; incurable metastatic disease; aged 20-75 years; an Eastern Cooperative Oncology Group performance status (PS) score of 0 or 1; and chemotherapy for metastatic breast cancer allowed up to one regimen. The exclusion criteria were HER2-positive breast cancer; patients with CIPN of grade $\geq 2$; and brain metastases with symptoms or requiring treatment.

Eligible patients were randomly assigned by dynamic allocation in a 1:1:1 ratio to receive any of 3 doses of nabPTX: standard dose (SD) $260 \mathrm{mg} / \mathrm{m}^{2}$, medium dose (MD) $220 \mathrm{mg} / \mathrm{m}^{2}$, and low dose (LD) $180 \mathrm{mg} / \mathrm{m}^{2}$. Stratification factors were a history of chemotherapy for metastatic disease (yes vs. no), hormone receptor status (positive vs. negative), history of taxane treatment including perioperative use (yes vs. no), relapse-free interval ( $<2$ vs. $\geq 2$ years), and participating institution.

The patient received the assigned dose of nab-PTX once every 3 weeks for 30 min until disease progression or adverse events prevented continued treatment. After starting the protocol treatment, if a patient developed grade 4 thrombocytopenia, grade 3 thrombocytopenia requiring blood transfusion, neutrophils $<500 / \mathrm{mm}^{3}$ lasting for $\geq 7$ days, or grade $\geq 3$ non-hematological toxicity (excluding nausea, vomiting, and diarrhea), the dose in the next course was reduced by one step to 220,180 and $140 \mathrm{mg} / \mathrm{m}^{2}$ for the SD, $\mathrm{MD}$ and LD groups, respectively. The target number of registrations was 138 [3].

All subjects gave written informed consent before enrollment in the study. The study was approved by the 
institutional ethics committee on human research at all participating medical institutions.

\section{QoL assessment}

QoL of the study population was assessed using the Japanese version of the Functional Assessment of Cancer Therapy-Taxane (FACT-Taxane) scale [5]. FACT-Taxane was developed to measure adverse events and QoL in patients undergoing taxane treatment. It consists of a 27 -item general cancer QoL measure (FACT-General) [7 for physical wellbeing (PWB), 7 for social and family well-being (SFWB), 6 for emotional well-being (EWB), and 7 for functional wellbeing (FWB)] and a 16-item taxane subscale, including an 11-item neurotoxicity subscale and 5 questions on symptoms related to arthralgia, myalgia, and skin discoloration. Each FACT-Taxane item or question has response choices from 0 ("not at all") to 4 ("very much"). Scores range from 0 to 172 and a higher score indicates better QoL. The Japanese version of EuroQol 5-dimension (EQ-5D)-3L was used for preference-based measures of QoL, and was scored using a conversion table for the Japanese population $[6,7]$.

Fatigue in cancer patients was assessed using the Cancer Fatigue Scale (CFS) [8]. The CFS was developed to measure fatigue in cancer patients in Japan, with 15 items in 3 subscales: 7 for physical (score range 0-28), 4 for affective (0-16), and 4 for cognitive (0-16) subscales. Comprehensive fatigue in cancer patients is calculated as the sum of the three domains. The score is $0-60$, and a higher score indicates that fatigue is noticeable.

All patients in the parent trial were invited to be a part of the QoL substudy. Self-administered questionnaires were distributed by medical staff to subjects and returned to the Comprehensive Support Project for Oncological Research data center by mail. The date of the investigation and the allowed survey period were at registration (study entry to the start of protocol treatment), and during the 2nd, 4th and 6th courses of protocol treatment. If treatment was discontinued due to disease progression, complications, exacerbations, or adverse events, QoL evaluation was discontinued.

\section{Analysis}

The target group for the QoL substudy analysis included all registered cases except those that 1) did not meet the eligibility criteria. 2) for whom no protocol treatment was performed, or 3) QoL evaluation was not performed before the start of protocol treatment. The response rate was defined as the number of responses collected/the number of expected responses. All questionnaires were quantified using a scoring manual, and basic statistics for each group and each survey point were calculated.
The hypothesis for QoL evaluation was that QoL at MD or LD would be better than at SD. The primary outcome of the QoL substudy was the FACT-Taxane Trial Outcome Index (TOI) in the second, fourth, and sixth courses of protocol treatment. FACT-Taxane TOI is a 40-item aggregate of the PWB, FWB, and taxane subscale, and is often used as a single clinical trial outcome index.

For comparison of scores calculated as continuous variables, analysis was performed using a mixed effects model for repeated measures (MMRM). The model used the scores obtained at each survey point, except baseline, as an outcome, and the baseline value, group, survey point, and interaction terms of group and survey point as explanatory variables. The least-squares mean square value at each survey point for each group with the $95 \%$ confidence interval (CI), the intergroup difference at each survey point with the 95\% CI, and the $P$ value were calculated. The $P$ value of the group-by-survey-point interaction was also calculated to test the overall treatment effect among the three treatment groups.

Missing data were not imputed. There were no multiple-comparison adjustments. All tests were two-sided, and $P<0.05$ was considered to be significant. SAS v. 9.3 was used for analysis.

\section{Results}

\section{Patients and characteristics}

From February 2015 through June 2018, a total of 141 eligible patients were enrolled in the parent study, and 136 patients (96\%) (44, 45 and 47 in the SD, MD, and LD groups, respectively) were included in QoL analysis (Fig. 1).

The characteristics of the patients in the QoL substudy are shown in Table 1. In the SD, MD and LD groups, the mean ages were 57.9, 58.4 and 57.6 years, and the mean body mass indexes (BMIs) were 25.2, 23.6 and $22.3 \mathrm{~kg} /$ $\mathrm{m}^{2}$, respectively, with significant differences among BMIs $(P=0.03)$. There was no significant difference in PS, estrogen receptor status, pre-treatment by chemotherapy, pretreatment by taxane, and comorbidities.

The response rates of questionnaire in the $2 \mathrm{nd}, 4 \mathrm{th}$, and 6th courses of protocol treatment were 98, 95 and $97 \%$ in the SD group, 98, 100 and $97 \%$ in the MD group, and 91, 97 and $94 \%$ in the LD group, respectively. Reasons for missing surveys are listed in Appendix Table A1.

\section{Taxane-related QoL}

Mean scores and standard deviations for FACT-Taxane, EQ-5D and CFS at each survey point are shown in Table 2. The baseline scores did not differ significantly among the 
Fig. 1 CONSORT diagram. $\mathrm{SD}, 260 \mathrm{mg} / \mathrm{m}^{2}$ of 3-week cycle nab-paclitaxel; MD, $220 \mathrm{mg} / \mathrm{m}^{2}$ of 3-week cycle nab-paclitaxel; $\mathrm{LD}, 180 \mathrm{mg} / \mathrm{m}^{2}$ of 3 -week cycle nab-paclitaxel

Table 1 Characteristics of patients in the quality of life substudy

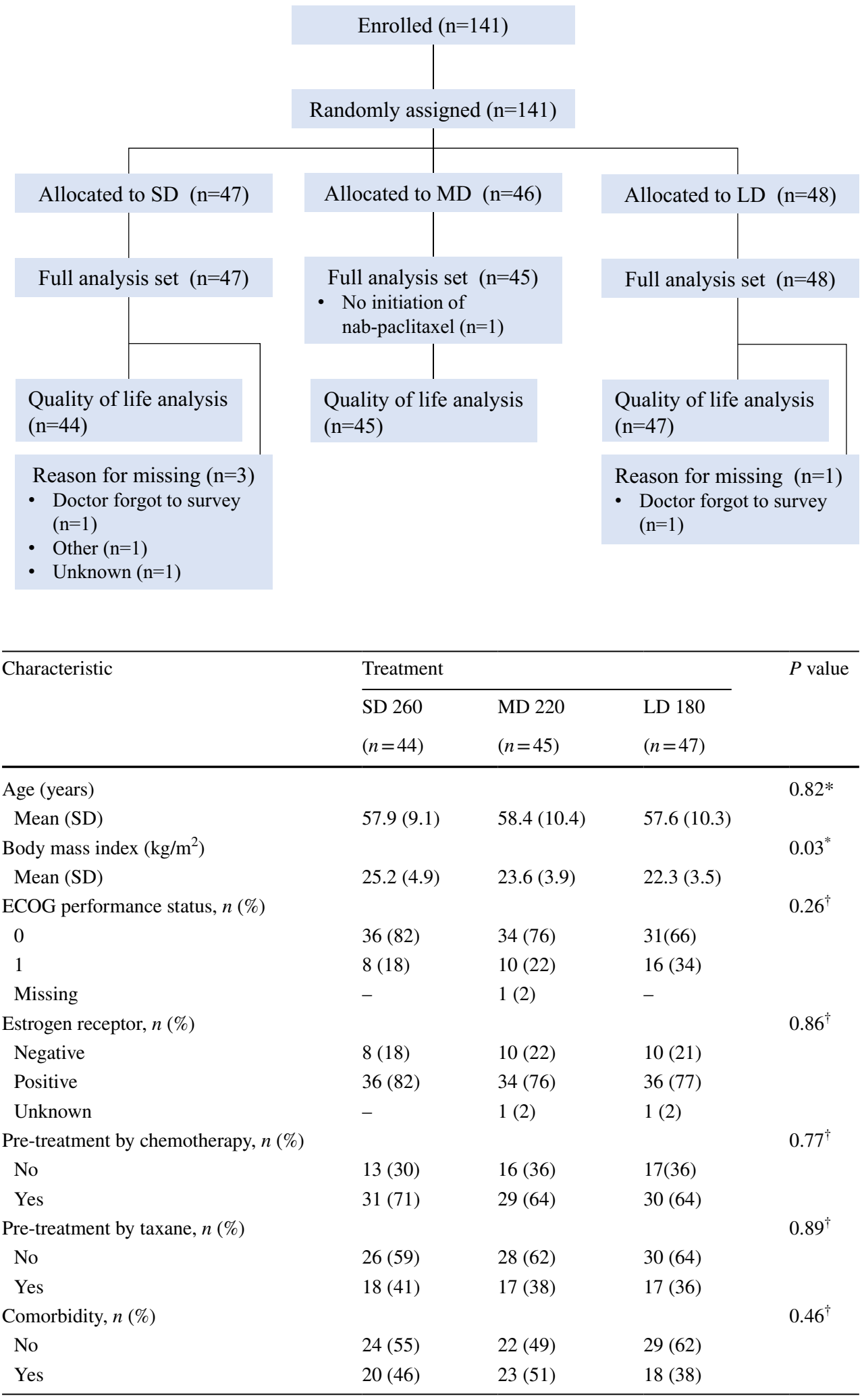

$S D 260260 \mathrm{mg} / \mathrm{m}^{2}$ of 3-week cycle nab-paclitaxel, $M D 220220 \mathrm{mg} / \mathrm{m}^{2}$ of 3-week cycle nab-paclitaxel, $L D$ $180180 \mathrm{mg} / \mathrm{m}^{2}$ of 3-week cycle nab-paclitaxel, SD standard deviation, ECOG Eastern Cooperative Oncology Group

*Kruskal-Wallis test

$\chi^{2}$ test 
Table 2 Mean scores at each survey point

\begin{tabular}{|c|c|c|c|c|c|c|c|c|}
\hline \multirow[t]{4}{*}{ Questionnaire } & \multirow[t]{4}{*}{ Survey point } & \multicolumn{6}{|c|}{ Treatment group } & \multirow[t]{4}{*}{$P$ value* } \\
\hline & & \multicolumn{6}{|c|}{ Number of responses, mean score (SD) } & \\
\hline & & \multicolumn{2}{|c|}{ SD 260} & \multicolumn{2}{|c|}{ MD 220} & \multicolumn{2}{|c|}{ LD 180} & \\
\hline & & \multicolumn{2}{|c|}{$(n=44)$} & \multicolumn{2}{|c|}{$(n=45)$} & \multicolumn{2}{|c|}{$(n=47)$} & \\
\hline \multicolumn{9}{|l|}{ FACT-Taxane } \\
\hline \multirow[t]{4}{*}{ Taxane total } & Baseline & 44 & $124.7(19.8)$ & 44 & $121.6(18.4)$ & 47 & $122.8(20.6)$ & 0.75 \\
\hline & 2nd course & 42 & $111.4(21.0)$ & 42 & $117.4(22.3)$ & 42 & $121.1(20.6)$ & \\
\hline & 4th course & 34 & $104.4(22.8)$ & 36 & $115.6(20.9)$ & 37 & $119.3(20.8)$ & \\
\hline & 6th course & 28 & $106.6(23.1)$ & 30 & $117.5(19.8)$ & 31 & $117.2(24.0)$ & \\
\hline \multirow[t]{4}{*}{ General total } & Baseline & 43 & $68.7(15.9)$ & 44 & $67.0(13.6)$ & 47 & $67.5(15.9)$ & 0.86 \\
\hline & 2nd course & 42 & $64.7(15.4)$ & 42 & $66.5(15.0)$ & 42 & $67.3(15.1)$ & \\
\hline & 4th course & 34 & $62.1(13.6)$ & 36 & $66.5(13.9)$ & 37 & $69.5(13.7)$ & \\
\hline & 6th course & 28 & $64.8(13.3)$ & 30 & $68.4(15.0)$ & 31 & $69.2(15.6)$ & \\
\hline \multirow[t]{4}{*}{ Taxane TOI } & Baseline & 44 & 93.4 (14.6) & 44 & $90.6(15.19)$ & 47 & $91.4(15.7)$ & 0.68 \\
\hline & 2nd course & 42 & 79.4 (17.7) & 42 & $86.2(18.9)$ & 42 & $89.4(16.4)$ & \\
\hline & 4th course & 34 & $73.3(19.3)$ & 36 & 83.7 (17.7) & 37 & $86.9(17.6)$ & \\
\hline & 6 th course & 29 & $72.3(22.4)$ & 30 & $85.2(16.0)$ & 31 & $84.6(18.3)$ & \\
\hline \multirow[t]{4}{*}{ PWB } & Baseline & 44 & $20.2(4.9)$ & 44 & $19.3(5.4)$ & 47 & $18.6(6.4)$ & 0.38 \\
\hline & 2nd course & 42 & $18.2(5.2)$ & 43 & $20.0(5.8)$ & 42 & $18.6(5.7)$ & \\
\hline & 4th course & 35 & $16.5(4.9)$ & 36 & $19.4(5.9)$ & 37 & $19.8(5.3)$ & \\
\hline & 6th course & 29 & $16.4(5.7)$ & 30 & $19.6(5.3)$ & 31 & $19.1(6.1)$ & \\
\hline \multirow[t]{4}{*}{ SFWB } & Baseline & 44 & $16.4(6.2)$ & 44 & $18.9(5.4)$ & 47 & $18.29(6.1)$ & 0.13 \\
\hline & 2 nd course & 42 & $16.2(6.1)$ & 42 & $17.0(6.3)$ & 42 & $17.4(6.1)$ & \\
\hline & 4th course & 35 & $15.5(6.1)$ & 36 & $16.4(6.0)$ & 37 & $16.3(6.6)$ & \\
\hline & 6th course & 28 & $16.3(5.2)$ & 30 & $16.9(6.7)$ & 31 & $16.9(6.1)$ & \\
\hline \multirow[t]{4}{*}{ EWB } & Baseline & 44 & $14.9(5.6)$ & 45 & $12.0(5.0)$ & 47 & $13.1(6.0)$ & 0.05 \\
\hline & 2nd course & 42 & $15.8(5.0)$ & 42 & $14.2(5.6)$ & 42 & $14.3(4.7)$ & \\
\hline & 4th course & 34 & $15.6(4.7)$ & 36 & $15.44(5.0)$ & 37 & $16.2(4.6)$ & \\
\hline & 6th course & 29 & $15.9(5.0)$ & 30 & $15.4(5.1)$ & 31 & $15.7(4.4)$ & \\
\hline \multirow[t]{4}{*}{ FWB } & Baseline & 44 & $16.7(6.8)$ & 45 & $16.70(5.1)$ & 47 & $17.5(5.4)$ & 0.74 \\
\hline & 2nd course & 42 & $14.5(6.7)$ & 42 & $15.5(5.9)$ & 42 & $17.0(6.2)$ & \\
\hline & 4th course & 34 & $14.5(5.76)$ & 36 & $15.3(5.2)$ & 37 & $17.3(5.4)$ & \\
\hline & 6th course & 29 & $15.0(5.9)$ & 30 & $16.5(6.1)$ & 31 & $17.5(5.3)$ & \\
\hline Taxane subscale & Baseline & 44 & $56.5(7.3)$ & 45 & $54.4(9.0)$ & 47 & $55.3(8.2)$ & 0.47 \\
\hline & 2nd course & 42 & $46.7(10.2)$ & 43 & $51.1(10.4)$ & 42 & $53.9(9.5)$ & \\
\hline & 4th course & 34 & $42.3(12.3)$ & 36 & $49.1(10.0)$ & 37 & $49.8(10.9)$ & \\
\hline & 6th course & 29 & 40.8 (13.6) & 30 & $49.1(8.5)$ & 31 & $48.0(10.2)$ & \\
\hline EQ-5D Utility & & & & & & & & \\
\hline & Baseline & 44 & $0.75(0.17)$ & 45 & $0.74(0.17)$ & 46 & $0.69(0.15)$ & 0.24 \\
\hline & 2 nd course & 42 & $0.67(0.15)$ & 43 & $0.76(0.18)$ & 42 & $0.72(0.17)$ & \\
\hline & 4th course & 34 & $0.64(0.15)$ & 36 & $0.73(0.18)$ & 37 & $0.72(0.17)$ & \\
\hline & 6th course & 29 & $0.67(0.15)$ & 30 & $0.72(0.16)$ & 31 & $0.72(0.16)$ & \\
\hline CFS & & & & & & & & \\
\hline Total & Baseline & 43 & $28.4(6.2)$ & 44 & $28.1(5.3)$ & 46 & $28.7(6.2)$ & 0.89 \\
\hline & 2nd course & 42 & $31.5(8.0)$ & 43 & $29.7(5.6)$ & 42 & $28.7(5.9)$ & \\
\hline & 4th course & 34 & $30.4(5.6)$ & 36 & $28.6(5.3)$ & 37 & $28.1(5.5)$ & \\
\hline & 6th course & 29 & $31.4(6.3)$ & 30 & $29.5(5.2)$ & 31 & 28.7 (6.6) & \\
\hline Physical & Baseline & 43 & $6.8(5.4)$ & 44 & $6.2(4.5)$ & 46 & $8.1(5.9)$ & 0.19 \\
\hline & 2nd course & 42 & $9.0(6.6)$ & 43 & $7.6(5.3)$ & 42 & $8.6(6.0)$ & \\
\hline & 4th course & 34 & $9.2(5.9)$ & 36 & $7.8(4.6)$ & 37 & $7.9(5.8)$ & \\
\hline & 6th course & 29 & $10.2(6.3)$ & 30 & $8.1(5.1)$ & 31 & $8.6(5.6)$ & \\
\hline
\end{tabular}


Table 2 (continued)

\begin{tabular}{|c|c|c|c|c|c|c|c|c|}
\hline \multirow[t]{4}{*}{ Questionnaire } & \multicolumn{7}{|c|}{ Survey point Treatment group } & \multirow[t]{4}{*}{$P$ value* } \\
\hline & & \multicolumn{6}{|c|}{ Number of responses, mean score (SD) } & \\
\hline & & \multicolumn{2}{|c|}{ SD 260} & \multicolumn{2}{|c|}{ MD 220} & \multicolumn{2}{|c|}{ LD 180} & \\
\hline & & \multicolumn{2}{|c|}{$(n=44)$} & \multicolumn{2}{|c|}{$(n=45)$} & \multicolumn{2}{|c|}{$(n=47)$} & \\
\hline \multirow[t]{4}{*}{ Affective } & Baseline & 43 & $8.7(3.1)$ & 44 & $8.6(3.1)$ & 46 & $8.3(3.7)$ & 0.86 \\
\hline & 2nd course & 42 & $9.2(3.3)$ & 43 & $8.9(2.8)$ & 42 & $8.0(3.9)$ & \\
\hline & 4th course & 34 & $9.0(2.3)$ & 36 & $8.4(3.4)$ & 37 & $8.1(3.6)$ & \\
\hline & 6th course & 29 & $8.9(2.5)$ & 30 & $9.0(2.9)$ & 31 & $8.1(3.5)$ & \\
\hline \multirow[t]{4}{*}{ Cognitive } & Baseline & 43 & $13.0(2.7)$ & 44 & $13.3(2.2)$ & 46 & $12.2(2.9)$ & 0.14 \\
\hline & 2nd course & 42 & $13.3(2.3)$ & 43 & $13.2(2.6)$ & 42 & $12.1(3.8)$ & \\
\hline & 4th course & 34 & $12.2(3.3)$ & 36 & $12.5(3.1)$ & 37 & $12.1(3.6)$ & \\
\hline & 6th course & 29 & $12.4(3.6)$ & 30 & $12.3(3.3)$ & 31 & $12.0(3.2)$ & \\
\hline
\end{tabular}

$S D$ standard deviation, $S D 260260 \mathrm{mg} / \mathrm{m}^{2}$ of 3-week cycle nab-paclitaxel, $M D 220220 \mathrm{mg} / \mathrm{m}^{2}$ of 3-week cycle nab-paclitaxel, $L D 180180 \mathrm{mg} / \mathrm{m}^{2}$ of 3-week cycle nab-paclitaxel, FACT-Taxane Functional Assessment of Cancer Therapy-Taxane, Taxane TOI Taxane trial outcome index, $P W B$ physical well-being, $S F W B$ social and family wellbeing, $E W B$ emotional well-being, $F W B$ functional well-being, $E Q-5 D$ EuroQol 5-dimension, $C F S$ Cancer Fatigue Scale.

*Baseline scores were compared by $t$ test

groups. The mean change from baseline and $95 \% \mathrm{CI}$ for each dose are shown in Appendix Figure A1.

In comparison of baseline-adjusted means by MMRM analysis between $\mathrm{SD}$ and $\mathrm{MD}$, there were significant differences in FACT-Taxane TOI (overall treatment effect, $P<0.001$ ) (Fig. 2). The estimated mean differences and $95 \% \mathrm{CI}$ between $\mathrm{SD}$ and MD in the FACT-Taxane TOI score change from baseline in the 2nd, 4th, and 6th course of treatment were 9.8 (3.9, 15.6), $12.1(5.9,18.4)$, and $16.2(9.7,22.8)$, and the taxanerelated QoL for MD was significantly better than that for SD during all observation periods. For other summary and domain scores, the estimated difference in the score change from baseline for MD was significantly higher for FACT-Taxane total $(P<0.001)$, taxane subscale $(P<0.001)$, PWB $(P=0.002)$, and EWB $(P=0.024)$. On the other hand, the SFWB score was significantly lower for MD than for $\mathrm{SD}(P=0.037)$ (Fig. 2). Significant differences between the groups were noted, especially for the PWB and taxane subscale.

In comparison of baseline-adjusted means by MMRM analysis between SD and LD, there were significant differences in FACT-Taxane TOI (overall treatment effect, $P<0.001$ ) (Fig. 2.). The estimated mean differences and 95\% CI between SD and LD for the FACT-Taxane TOI score change from baseline to the 2nd, 4th, and 6th courses of treatment were 11.6 (5.8, 17.4), 15.3 (9.1, 21.4), and 16.5 (10.0, 23.0), and taxane-related QoL for LD was significantly better than that for SD during all observation periods. For other summary and domain scores, the estimated difference of the score change from baseline for $\mathrm{LD}$ was significantly higher for FACT-Taxane total $(P<0.001)$, FACT-General total $(P<0.011)$, taxane subscale $(P<0.001)$, PWB $(P<0.001)$, and EWB $(P=0.004)$ (Fig. 2). Significant differences between the groups were noted, especially for the PWB and taxane subscale.
In a comparison of baseline-adjusted means by MMRM analysis, there were significant differences in EQ-5D utility scores between SD and MD $(P=0.011)$, and SD and LD $(P<0.001)$ (Fig. 3). This reveals that preference-based QoL for MD and LD was also significantly better than that for SD during all observation periods.

\section{Cancer fatigue}

The mean change from baseline and 95\% CI for each dose are shown in Appendix Figure A2. In comparison of baselineadjusted means by MMRM analysis, these variables showed no significant differences at SD and MD (Fig. 4). However, there were significant differences between SD and LD for CFS total score $(P=0.013)$, and physical $(P=0.001)$ and cognitive $(P=0.033)$ subscores (Fig. 4). The estimated mean differences and $95 \% \mathrm{CI}$ between SD and LD in the CFS total score change from baseline to the second, fourth, and sixth courses of treatment were $-3.0(-5.3,-0.8),-2.9(-5.2,-0.5)$, and $-3.5(-6.0$, $-1.0)$. These data revealed that cancer fatigue for LD was significantly milder than that for SD during all observation periods.

\section{Discussion}

This is the first study comparing QoL with $260 \mathrm{mg} / \mathrm{m}^{2}$ of q3w nab-PTX to that with $220 \mathrm{mg} / \mathrm{m}^{2}$ or $180 \mathrm{mg} / \mathrm{m}^{2}$ of q3w nab-PTX in patients with metastatic breast cancer. PROs in the clinical trial were assessed using FACT-Taxane as a taxane-related QoL scale, CFS as a cancer-related fatigue scale, and EQ-5D as a preference-based comprehensive health assessment scale. 
A FACT-Taxane TOI

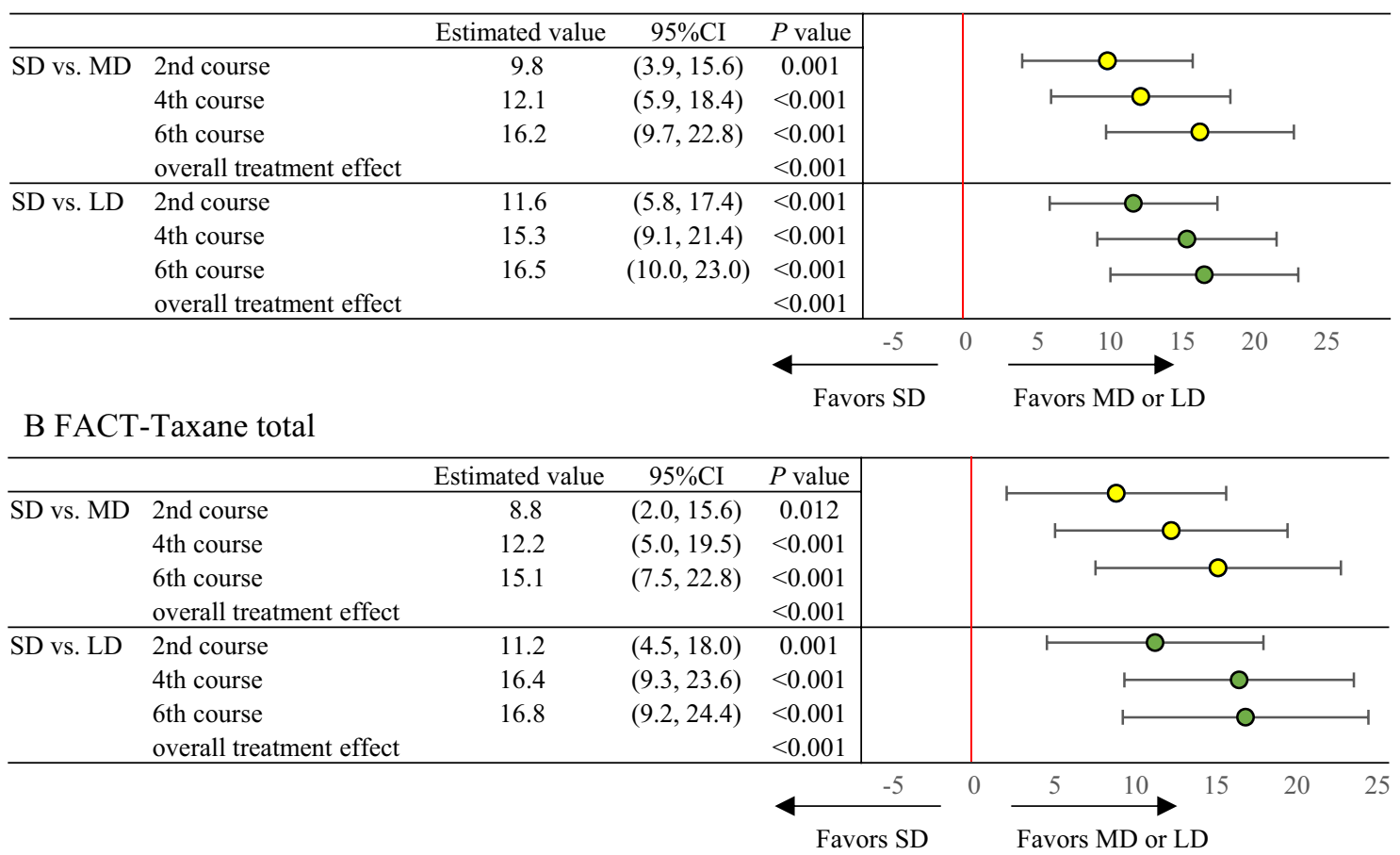

C FACT-General total

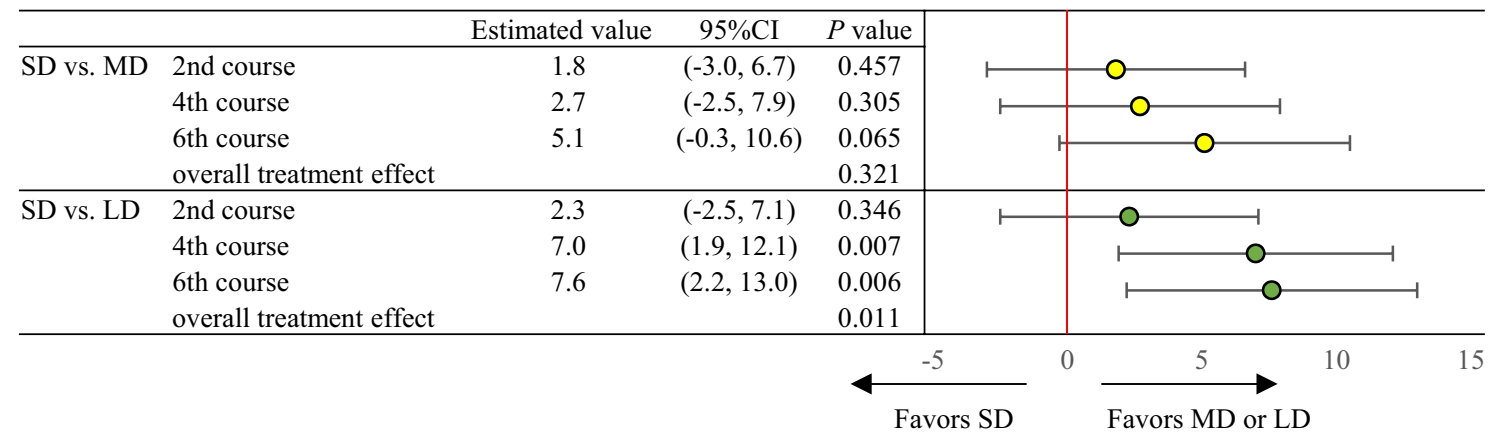

D Taxane subscale

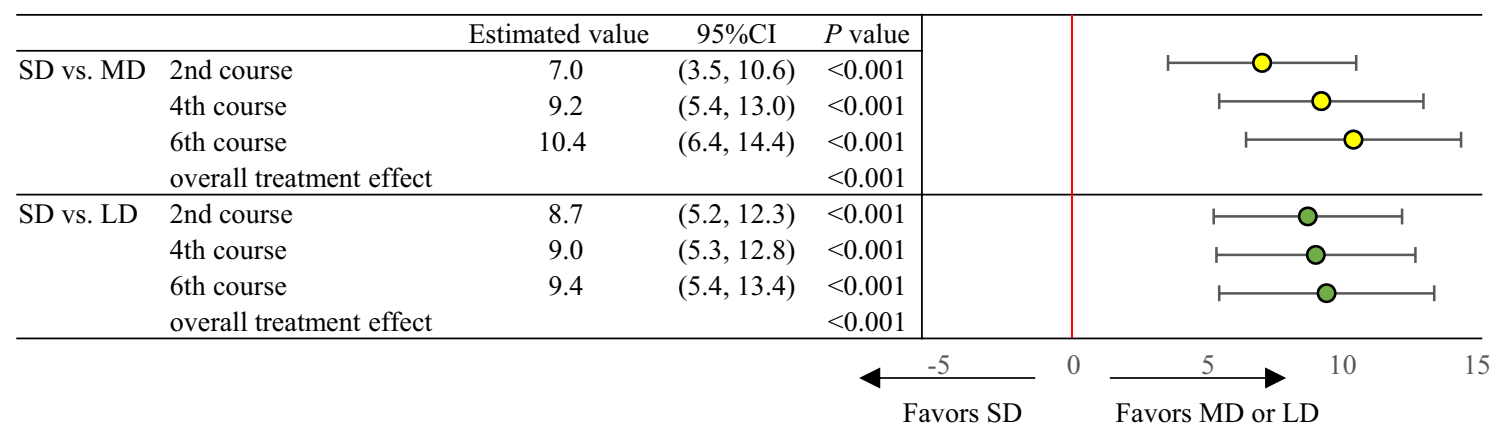

Fig. 2 Estimates of mean differences and 95\% confidence intervals for changes in A Functional Assessment of Cancer Therapy-Taxane trial outcome index (FACT-Taxane TOI), B FACT-Taxane total, C FACT-General total, and D Taxane subscale, $\mathbf{E}$ physical well-being (PWB), F social and family well-being (SFWB), G emotional well- being (EWB), H functional well-being (FWB) scores, compared to $\mathrm{SD}\left(260 \mathrm{mg} / \mathrm{m}^{2}\right.$ of 3 -week cycle nab-paclitaxel) in a mixed effects model for repeated measures. MD, $220 \mathrm{mg} / \mathrm{m}^{2}$ of 3-week cycle nabpaclitaxel; $\mathrm{LD}, 180 \mathrm{mg} / \mathrm{m}^{2}$ of 3-week cycle nab-paclitaxel 
E PWB

\begin{tabular}{|c|c|c|c|c|c|c|}
\hline & & Estimated value & $95 \% \mathrm{CI}$ & $P$ value & \multirow[b]{2}{*}{$\longmapsto-1$} & \\
\hline \multirow[t]{4}{*}{ SD vs. MD } & 2nd course & 2.5 & $(0.3,4.6)$ & 0.023 & & \\
\hline & 4th course & 3.2 & $(1.0,5.5)$ & 0.005 & \multirow{3}{*}{$\stackrel{\mathrm{O}}{\mathrm{O}}$} & \\
\hline & 6th course & 4.3 & $(2.0,6.7)$ & $<0.001$ & & \\
\hline & overall treatment effect & & & 0.002 & & \\
\hline \multirow[t]{4}{*}{ SD vs. LD } & 2 nd course & 1.7 & $(-0.4,3.8)$ & 0.121 & 0 & \\
\hline & 4th course & 4.5 & $(2.2,6.7)$ & $<0.001$ & $\longmapsto 0$ & \\
\hline & 6th course & 4.8 & $(2.5,7.2)$ & $<0.001$ & \multirow[t]{2}{*}{$\longmapsto 0$} & \\
\hline & overall treatment effect & & & $<0.001$ & & \\
\hline \multicolumn{5}{|r|}{-} & \multirow[b]{2}{*}{ is MD or LD } & 10 \\
\hline & & & & & & \\
\hline
\end{tabular}

SFWB

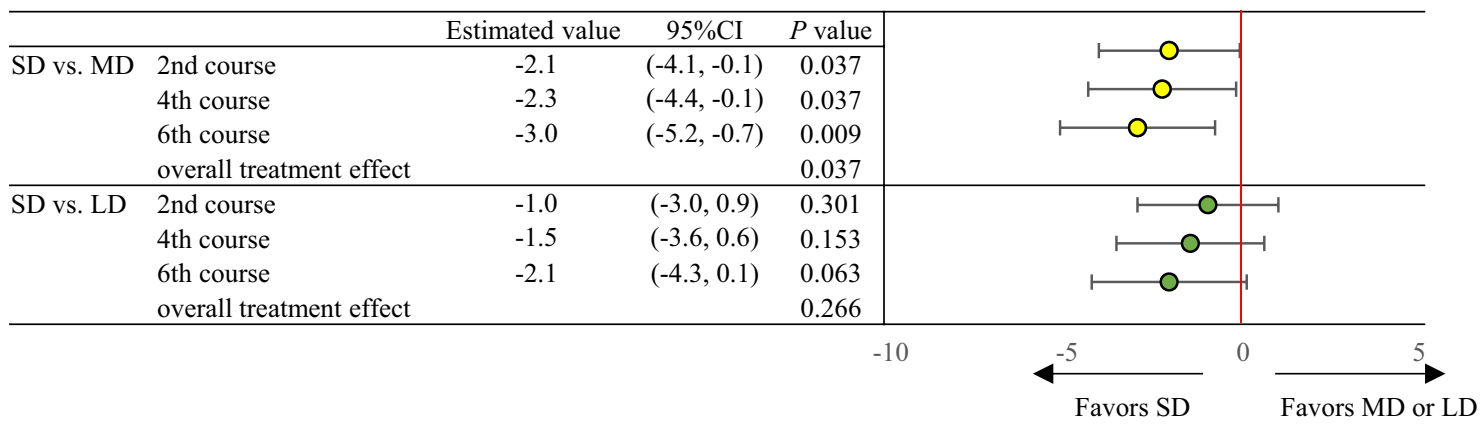

\section{G EWB}

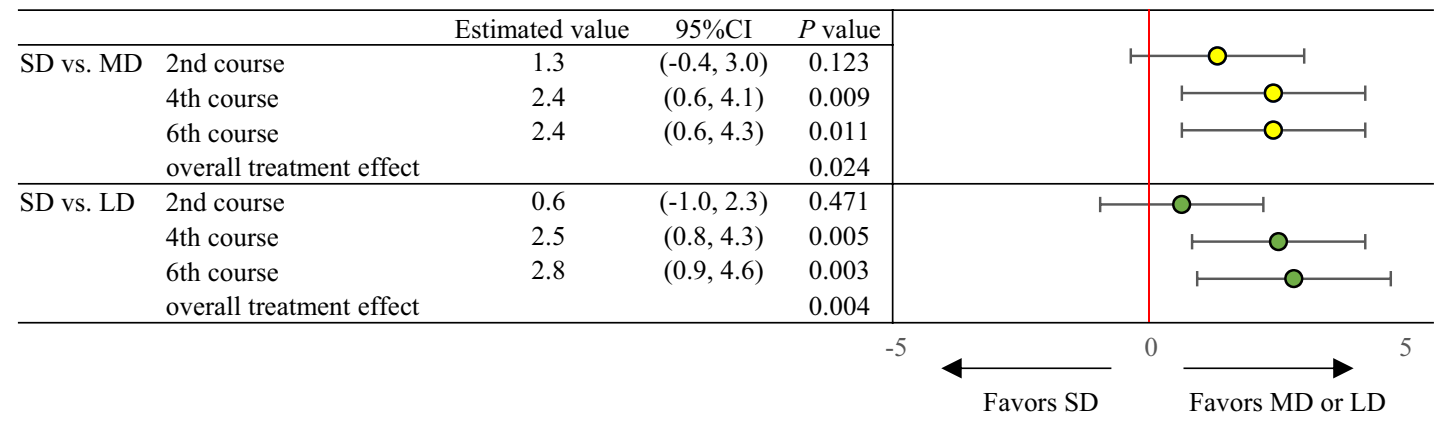

\section{H FWB}

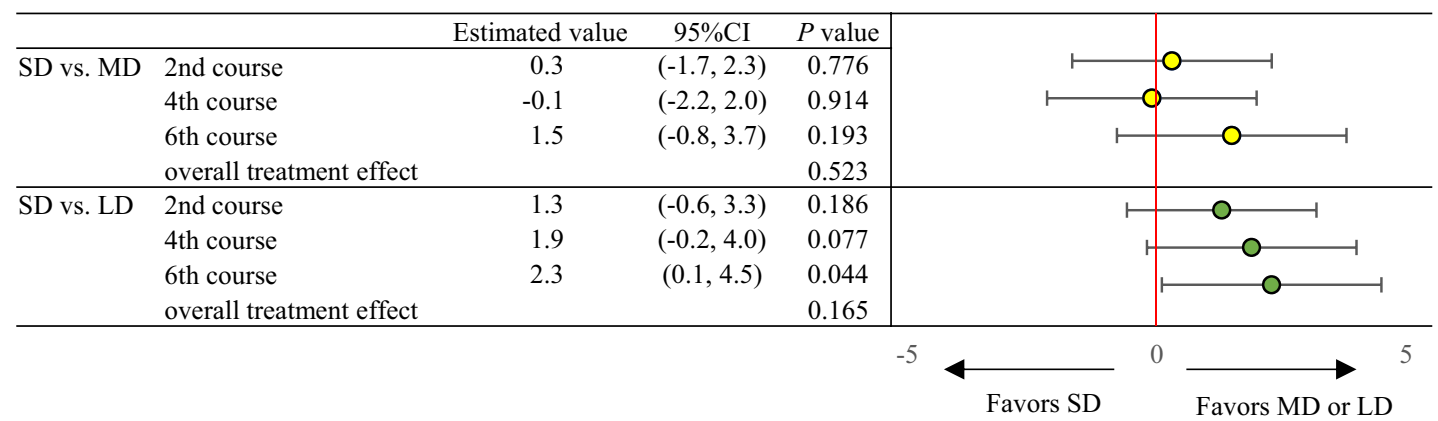

Fig. 2 (continued) 


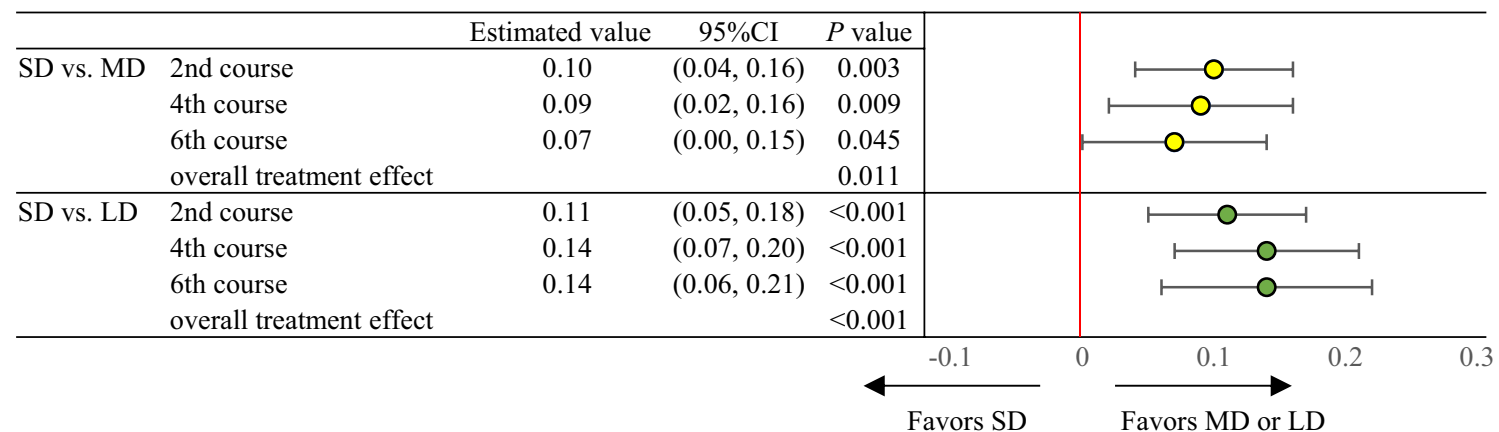

Fig. 3 Estimates of mean differences and 95\% confidence intervals for changes in EuroQol 5-Dimension (EQ-5D) scores, compared to $\mathrm{SD}\left(260 \mathrm{mg} / \mathrm{m}^{2}\right.$ of 3 -week cycle nab-paclitaxel $)$ in a mixed effects

We found that the initial dose of $\mathrm{q} 3 \mathrm{w}$ nab-PTX had a significant effect on taxane-related QoL and cancer fatigue. QoL of patients with metastatic breast cancer treated with $260 \mathrm{mg} /$ $\mathrm{m}^{2}$ of $\mathrm{q} 3 \mathrm{w}$ nab-PTX was significantly worse compared to those treated with 220 or $180 \mathrm{mg} / \mathrm{m}^{2}$ of q3w nab-PTX, and significant differences between the groups were noted, especially for the PWB and taxane subscale. Many of the QoL constituent domains showed a positive trend with low-dose nab-PTX, but SFWB showed the opposite trend, for unknown reasons. Primary endpoint analysis showed that intravenous administration of low-dose nab-PTX at $180 \mathrm{mg} / \mathrm{m}^{2} \mathrm{q} 3 \mathrm{w}$ may be the optimal therapy with meaningful efficacy and favorable toxicity for patients with metastatic breast cancer [4]. The QoL substudy also showed that low-dose nab-PTX at $180 \mathrm{mg} /$ $\mathrm{m}^{2} \mathrm{q} 3 \mathrm{w}$ is optimal in terms of QoL and cancer-related fatigue.

Standard doses of chemotherapeutic agents should be determined based on risk and benefit balance. However, in terms of dose intensity, the standard dose is often determined by acute toxicities such as hematologic toxicity, diarrhea, and vomiting during development of the drug. Regarding the cumulative toxicity of chemotherapy, a strategy of continuing treatment by short-term drug withdrawal or reducing the dose is used based on observation of adverse events. However, some adverse effects of chemotherapy are not easily improved by withdrawing or reducing the dose of chemotherapy, and CIPN is an example. In a discussion at the start of the study, treatment with nab-PTX using drug reduction and withdrawal was suggested to be optimal. However, we obtained a result that overturned this opinion, since we found that the initial dose of nab-PTX has a significant effect on subsequent patient QoL.

CIPN is a major clinical challenge due to lack of effective treatment and impact on QoL [9]. There are no drugs for preventing or ameliorating CIPN in a long-term course, and chemotherapy schedule modification is often required to limit its severity; however, this also may limit the efficacy of the cancer treatment. Moreover, symptomatic therapy is often ineffective in reducing CIPN symptoms [10]. Taxanes model for repeated measures. MD, $220 \mathrm{mg} / \mathrm{m}^{2}$ of 3-week cycle nabpaclitaxel; LD, $180 \mathrm{mg} / \mathrm{m}^{2}$ of 3-week cycle nab-paclitaxel

are representative chemotherapeutic agents that induce CIPN. Taxanes inhibit depolymerization of microtubules $[11,12]$, and CIPN may be caused by the resulting abnormal aggregation of microtubules in neuronal cells. Polyoxyethylated castor oil, which is used as a vehicle for taxanes, may also increase the risk for prolonged peripheral neuropathy [13]. Animal studies have shown that the time to recovery from CIPN depends on the drug, and that the morphological effect on axons in PTX-treated animals is long lasting [14].

Nab-PTX is an albumin-bound, nanoparticle formulation of PTX that was developed to reduce the incidence of CIPN compared to that with conventional taxanes $[15,16]$. However, in the CA012-0 trial, a phase III study comparing 3-week cycles of nab-PTX $\left(260 \mathrm{mg} / \mathrm{m}^{2}\right)$ and so-PTX $\left(175 \mathrm{mg} / \mathrm{m}^{2}\right)$ in patients with metastatic breast cancer, CIPN occurred more frequently with nab-PTX, despite nab-PTX showing greater efficacy in terms of RR [1]. In contrast, superiority of nab-PTX over so-PTX in PFS was not found in patients with metastatic breast cancer in the CALGB40502 phase III trial, and hematologic toxicity of grade $\geq 3$ and CIPN occurred more frequently with nab-PTX [17]. Dose reduction was more common and occurred earlier with nabPTX, and discontinuation rates were also higher. Therefore, it was concluded that the dose of nab-PTX used in the study $\left(150 \mathrm{mg} / \mathrm{m}^{2} /\right.$ week) was not appropriate and resulted in significant toxicity. These studies indicate that the initial dose of nab-PTX can cause adverse events that may have a long recovery time and a significant effect on patient outcomes, consistent with the findings obtained in this study.

Cancer-related fatigue causes disruption of all aspects of QoL and may be a risk factor for reduced survival [18]. Fatigue may be elevated before treatment onset and typically increases during cancer treatment, including that with radiation, chemotherapy, hormonal, and/or biological therapies. The rate of cancer-related fatigue ranges from 4 to $91 \%$, depending on the population studied and the methods of assessment [19]. In a RCT comparing taxanes and S-1 in patients with metastatic breast cancer in Japan, the 


\section{A CFS total}

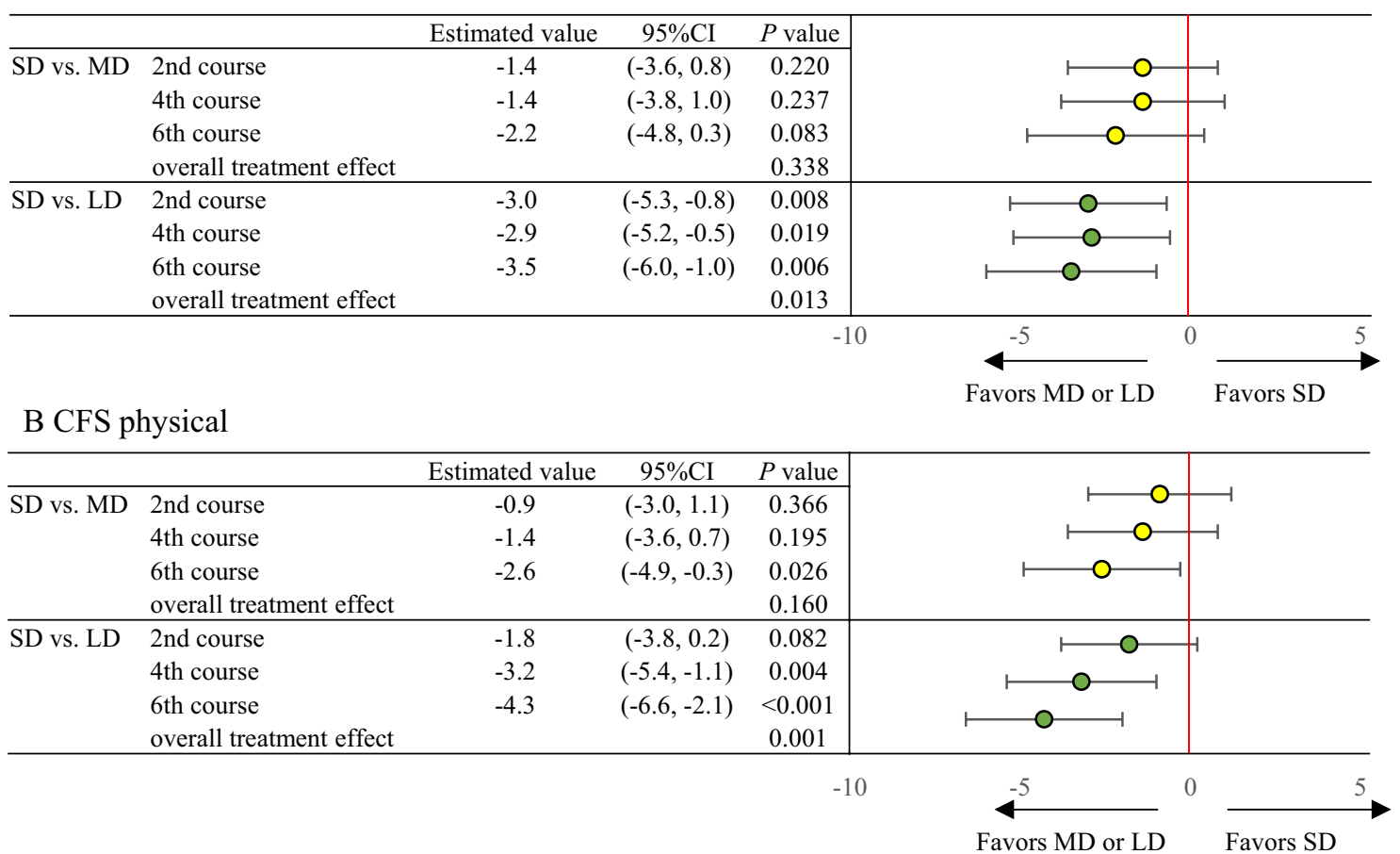

C CFS affective

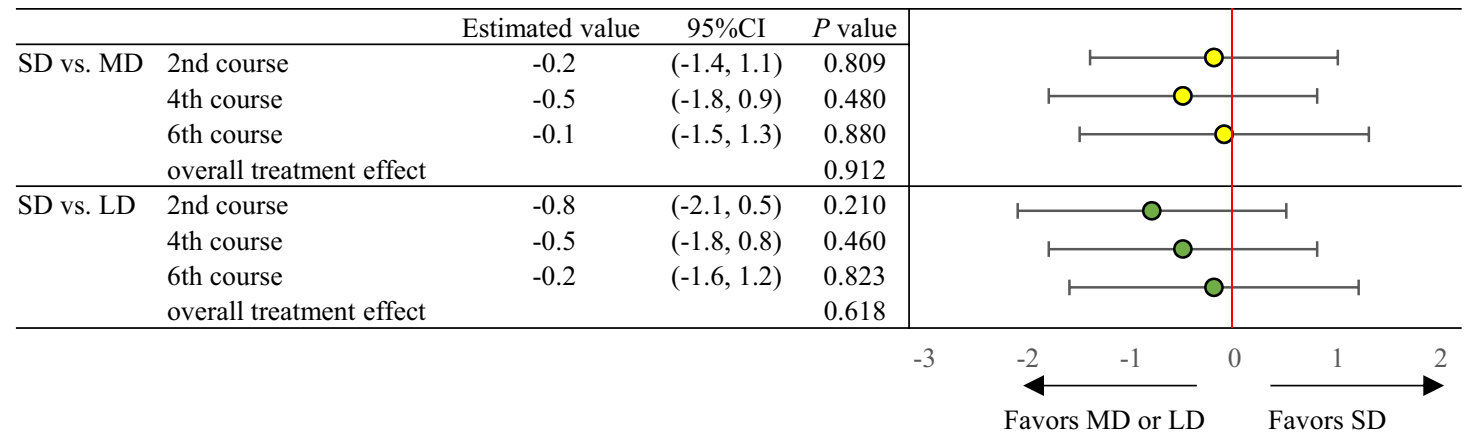

D CFS cognitive

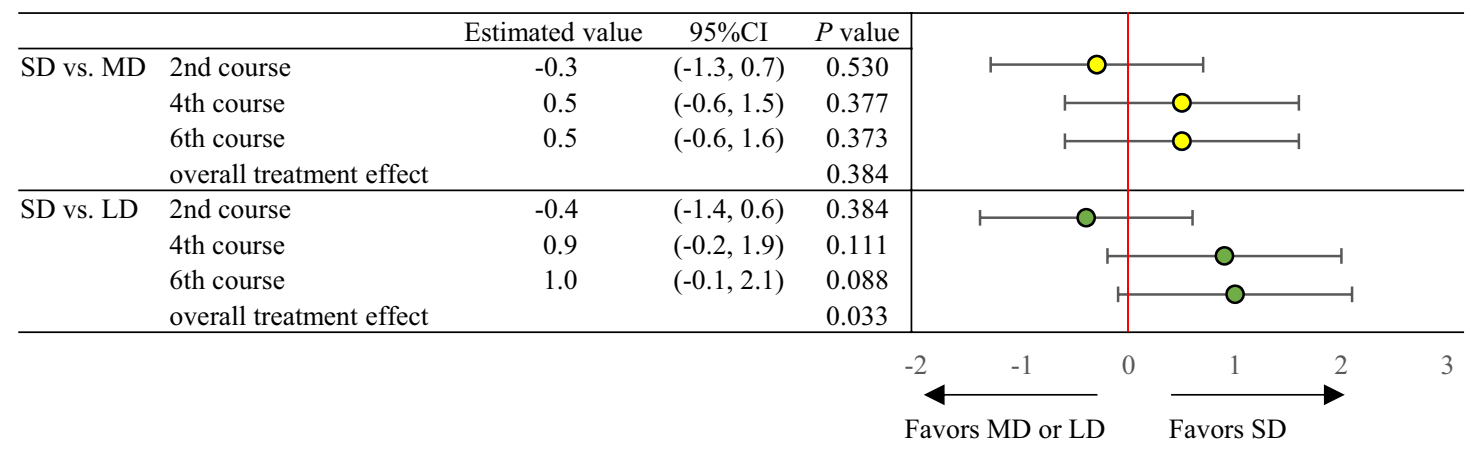

Fig. 4 Estimates of mean changes and 95\% confidence interval for $\mathbf{A}$ Cancer Fatigue Scale (CFS) total, $\mathbf{B}$ physical, $\mathbf{C}$ affective, and $\mathbf{D}$ cognitive scores, compared to SD $\left(260 \mathrm{mg} / \mathrm{m}^{2}\right.$ of 3 -week cycle nab-pacli- taxel) by mixed effects model for repeated measures. MD, $220 \mathrm{mg} /$ $\mathrm{m}^{2}$ of 3-week cycle nab-paclitaxel; $\mathrm{LD}, 180 \mathrm{mg} / \mathrm{m}^{2}$ of 3-week cycle nab-paclitaxel 
frequency of fatigue in the taxane group was approximately $50 \%$ in all grades [20]. However, these data are based on physician's assessments, which may be underreported, and the actual rate of fatigue in taxane-based chemotherapy for metastatic breast cancer is likely to be higher [21]. Fatigue in cancer patients is multifactorial and may be influenced by demographic, medical, psychosocial, behavioral, and biological factors [18]. Nevertheless, the initial dose of nab-PTX had a significant effect on subjective fatigue in this study, especially for physical fatigue. At the current standard dose of $260 \mathrm{mg} / \mathrm{m}^{2}$, physical fatigue worsened over the course of treatment, but no worsening tendency was observed at 220 or $180 \mathrm{mg} / \mathrm{m}^{2}$. Cancer fatigue in metastatic breast cancer patients treated with low-dose nab-PTX at $180 \mathrm{mg} / \mathrm{m}^{2} \mathrm{q} 3 \mathrm{w}$ was significantly milder than that in patients treated with standard dose nab-PTX.

Both CIPN and fatigue are symptoms that are difficult for physicians to evaluate accurately, and in clinical trials, the discrepancy between physicians' assessments and patients reported outcomes (PROs) can be a problem [21]. In a RCT of adjuvant chemotherapy with taxanes for breast cancer, a substudy of the agreement between physician and patient assessments for CIPN gave kappa coefficients for sensory and motor symptoms of 0.16 and 0.22 , which are extremely low [22]. In a comparative study of clinician and patient assessment of symptoms in lung cancer patients, $41 \%$ of clinicians underreported symptoms of fatigue compared to patient reports [23]. Therefore, as the results of this study indicate, there is a limit to the therapeutic strategy of monitoring the cumulative toxicity associated with chemotherapy by physician assessment and reducing the dose or withdrawing the drug when this toxicity becomes significant. If a treatment strategy is to truly maintain and improve QoL, it is essential to monitor PROs in daily clinical practice [24]. It is also important to verify the dose that achieves the optimal risk and benefit balance after marketing of a new chemotherapeutic agent, particularly for drugs with cumulative toxicity.

A limitation of this study is that it is based on a secondary endpoint of a small randomized phase 2 trial, with no adjustment for multiple tests. Also, a relatively short-term evaluation up to the sixth cycle was used, and long-term effects were not examined. Furthermore, a weekly schedule of nab-PTX is more commonly used to treat patients with breast cancer, and the significance of our findings for the reduced dose of $\mathrm{q} 3 \mathrm{w}$ nab-PTX may be limited. NabPTX at $100 \mathrm{mg} / \mathrm{m}^{2}$ can be administered weekly to reduce the incidence and degree of myalgia. Nonetheless, it was not until recently that the weekly nab-PTX regimen was adopted in Japan for treatment of patients with metastatic breast cancer due to previous failures to demonstrate its superiority to $\mathrm{q} 3 \mathrm{w}$ docetaxel in terms of PFS [25]. There should be room for less frequent regimens, especially in patients with limited access to clinics or in those who might benefit from minimizing the risk of coronavirus infection during the COVID-19 pandemic.

In conclusion, the initial dose of nab-PTX affects subsequent taxane-related QoL, as well as cancer-related fatigue. Low dose nab-paclitaxel at $180 \mathrm{mg} / \mathrm{m}^{2} \mathrm{q} 3 \mathrm{w}$ may be an optimal dose in terms of PFS, taxane-related QoL and cancer-related fatigue. Further evaluation is warranted to confirm these findings in a larger trial.

Supplementary Information The online version contains supplementary material available at https://doi.org/10.1007/s12282-021-01290-5.

Acknowledgements This work was supported by a Comprehensive Support Project Award for Oncology Research in Breast Cancer (CSPOR-BC). The authors would like to thank all the patients who participated in the ABROAD trial and their families. We also thank the investigators and research coordinators at the 41 participating institutions. We are also grateful to Ms. H. Shinano for the administrative support required to carry out this research.

Author contributions Conceptualization: FH, HM and NT. Methodology: FH, KK, TS, NT, TT and JT. Software and formal analysis: KK. Investigation: NT, JT, MK, MT, HK. YK, ES, YN, YH, TS, TI, TT, TA, HM and FH. Data curation: TA. Writing of original draft: NT and KK. Reviewing and editing: all authors. Visualization: YA, NT, KK and FH. Supervision: HM. Data curation: FH and KK. Project administration: FH. Funding acquisition: FH and HM.

Funding The ABROAD study was sponsored by the Comprehensive Support Project for Oncology Research in Breast Cancer, with research funds provided by Taiho Pharmaceutical under the study contract. Taiho Pharmaceutical took no part in this study other than providing information relevant to proper use of the study drug.

\section{Declarations}

Conflict of interest Junji Tsurutani has received research funds from Daiichi Sankyo; honoraria from Novartis, Taiho, Eisai, Chugai, and Kyowa Kirin; personal fees for participating in advisory boards for Eisai and Asahi Kasei; and support for travel expenses from Daiichi Sankyo. Masato Takahashi has received an honorarium for a lecture from Taiho. Yoichi Naito has received research funds from Roche Diagnostics; and honoraria for lectures from Roche Diagnostics, Novartis, Eisai, Chugai Pharmaceutical, Fuji Film Toyama Chemistry, and Taiho. Hirofumi Mukai has received honoraria from Pfizer, Takeda, Daiichi Sankyo and Taiho; and research grants from the Japanese government, Daiichi Sankyo, and Pfizer. Hirofumi Mukai is a member of the Board of Directors of the Japan Breast Cancer Society.

Ethics approval This study was reviewed and approved by independent ethics committees and institutional review boards. Written informed consent was obtained from all patients.

Data sharing Due to the nature of this research, participants in the study did not agree for their data to be shared publicly, so supporting data are not available. 


\section{References}

1. Gradishar WJ, Tjulandin S, Davidson N, Shaw H, Desai N, Bhar $\mathrm{P}$, et al. Phase III trial of nanoparticle albumin-bound paclitaxel compared with polyethylated castor oil-based paclitaxel in women with breast cancer. J Clin Oncol. 2005;31:7794-803. https://doi. org/10.1200/JCO.2005.04.937.

2. Nakamura S, Iwata H, Funato Y, Ito K. Ito Y [Results of a drug use investigation of nanoparticle albumin-bound paclitaxel for breast cancer]. Gan To Kagaku Ryoho. 2015;42:447-55.

3. Hara F, Takashima T, Tsurutani J, Saito T, Taira N, Kashiwabara $\mathrm{K}$, et al. Randomized, optimal dose finding, phase II study of triweekly nab-paclitaxel in patients with metastatic breast cancer (ABROAD). J Clin Trials. 2016;6:267. https://doi.org/10.4172/ 2167-0870.1000267.

4. Tsurutani J, Hara F, Kitada M, Takahashi M, Kikawa Y, Kato H, et al. Randomized phase II study to determine the optimal dose of 3-week cycle nab-paclitaxel in patients with metastatic breast cancer. Breast. 2020;55:63-8. https://doi.org/10.1016/j.breast. 2020.12.002.

5. Cella D, Peterman A, Hudgens S, Webster K, Socinski MA. Measuring the side effects of taxane therapy in oncology: the functional assessment of cancer therapy-taxane (FACT-taxane). Cancer. 2003;98:822-31. https://doi.org/10.1002/cncr.11578.

6. Brooks R. EuroQol: the current state of play. Health Policy. 1996;37:58-72. https://doi.org/10.1016/0168-8510(96)00822-6.

7. Tsuchiya A, Ikeda S, Ikegami N, Nishimura S, Sakai I, Fukuda T, et al. Estimating an EQ-5D population value set: the case of Japan. Health Econ. 2002;11:341-53. https://doi.org/10.1002/hec.673.

8. Okuyama T, Akechi T, Kugaya A, Okamura H, Shima Y, Maruguchi M, et al. Development and validation of the Cancer Fatigue Scale: a brief, three-dimensional, self-rating scale for assessment of fatigue in cancer patients. J Pain Symptom Manag. 2000;19:514. https://doi.org/10.1016/s0885-3924(99)00138-4.

9. Mols F, Beijers T, Vreugdenhil G, van de Poll-Franse L. Chemotherapy-induced peripheral neuropathy and its association with quality of life: a systematic review. Support Care Cancer. 2014;22:2261-9. https://doi.org/10.1007/s00520-014-2255-7.

10. Cavaletti G, Marmiroli P. Chemotherapy-induced peripheral neurotoxicity. Nat Rev Neurol. 2010;6:657-66. https://doi.org/ 10.1038/nrneurol.2010.160.

11. Parness J, Horwitz SB. Taxol binds to polymerized tubulin in vitro. J Cell Biol. 1981;91:479-87. https://doi.org/10.1083/ jcb.91.2.479.

12. Schiff PB, Fant J, Horwitz SB. Promotion of microtubule assembly in vitro by taxol. Nature. 1979;277:665-7. https://doi.org/10. 1038/277665a0.

13. Roytta M, Raine CS. Taxol-induced neuropathy: further ultrastructural studies of nerve fibre changes in situ. J Neurocytol. 1985;14:157-75. https://doi.org/10.1007/BF01150269.

14. Cook BM, Wozniak KM, Proctor DA, Bromberg RB, Wu Y, Slusher BS, et al. Differential morphological and biochemical recovery from chemotherapy-induced peripheral neuropathy following paclitaxel, ixabepilone, or eribulin treatment in mouse sciatic nerves. Neurotox Res. 2018;34:677-92. https://doi.org/ 10.1007/s12640-018-9929-8.

15. Yardley DA. nab-Paclitaxel mechanisms of action and delivery. $\mathbf{J}$ Control Release. 2013;170:365-72. https://doi.org/10.1016/j.jconr el.2013.05.041.
16. Desai N, Trieu V, Yao Z, Louie L, Ci S, Yang A, et al. Increased antitumor activity, intratumor paclitaxel concentrations, and endothelial cell transport of cremophor-free, albumin-bound paclitaxel, ABI-007, compared with cremophor-based paclitaxel. Clin Cancer Res. 2006;12:1317-24. https://doi.org/10.1158/10780432.CCR-05-1634.

17. Rugo HS, Barry WT, Moreno-Aspitia A, Lyss AP, Cirrincione C, Leung E, et al. Randomized phase III trial of paclitaxel once per week compared with nanoparticle albumin-bound nab-paclitaxel once per week or ixabepilone with bevacizumab as first-line chemotherapy for locally recurrent or metastatic breast cancer: CALGB 40502/NCCTG N063H (Alliance). J Clin Oncol. 2015;33:2361-9. https://doi.org/10.1200/JCO.2014.59.5298.

18. Bower JE. Cancer-related fatigue: mechanisms, risk factors, and treatments. Nat Rev Clin Oncol. 2014;11:597-609. https://doi.org/ 10.1038/nrclinonc.2014.127.

19. Lawrence DP, Kupelnick B, Miller K, Devine D, Lau J. Evidence report on the occurrence, assessment, and treatment of fatigue in cancer patients. J Natl Cancer Inst Monogr. 2004;32:40-50. https://doi.org/10.1093/jncimonographs/lgh027.

20. Takashima T, Mukai H, Hara F, Matsubara N, Saito T, Takano T, SELECT BC Study Group, et al. Taxanes versus S-1 as the firstline chemotherapy for metastatic breast cancer (SELECT BC): an open-label, non-inferiority, randomised phase 3 trial. Lancet Oncol. 2015;17:90-8. https://doi.org/10.1016/S1470-2045(15) 00411-8.

21. Seruga B, Templeton AJ, Badillo FE, Ocana A, Amir E, Tannock IF. Under-reporting of harm in clinical trials. Lancet Oncol. 2016;17:e209-19. https://doi.org/10.1016/S1470-2045(16) 00152-2.

22. Shimozuma K, Ohashi Y, Takeuchi A, Aranishi T, Morita S, Kuroi K, et al. Feasibility and validity of the Patient Neurotoxicity Questionnaire during taxane chemotherapy in a phase III randomized trial in patients with breast cancer: N-SAS BC 02 . Support Care Cancer. 2019;17:1483-91. https://doi.org/10.1007/ s00520-009-0613-7.

23. Basch E, Iasonos A, McDonough T, Barz A, Culkin A, Kris MG, et al. Patient versus clinician symptom reporting using the National Cancer Institute Common Terminology Criteria for Adverse Events: results of a questionnaire-based study. Lancet Oncol. 2006;7:903-9. https://doi.org/10.1016/S1470-2045(06) 70910-X.

24. LeBlanc TW, Abernethy AP. Patient-reported outcomes in cancer care: hearing the patient voice at greater volume. Nat Rev Clin Oncol. 2017;14:763-72. https://doi.org/10.1038/nrclinonc.2017. 153.

25. Tamura K, Inoue K, Masuda N, Takao S, Kashiwaba M, Tokuda $\mathrm{Y}$, et al. Randomized phase II study of nab-paclitaxel as first-line chemotherapy in patients with HER2-negative metastatic breast cancer. Cancer Sci. 2017;108:987-94. https://doi.org/10.1111/cas. 13221.

Publisher's Note Springer Nature remains neutral with regard to jurisdictional claims in published maps and institutional affiliations. 


\section{Authors and Affiliations}

\section{Naruto Taira ${ }^{1}\left(\mathbb{D} \cdot\right.$ Kosuke Kashiwabara $^{2} \cdot$ Junji Tsurutani $^{3} \cdot$ Masahiro Kitada $^{4} \cdot$ Masato Takahashi $^{5} \cdot$ Hiroaki Kato $^{6}$.} Yuichiro Kikawa $^{7}$. Eiko Sakata ${ }^{8}$. Yoichi Naito ${ }^{9}$. Yoshie Hasegawa ${ }^{10}$. Tsuyoshi Saito ${ }^{11}$. Tsutomu Iwasa ${ }^{12}$.

Tsutomu Takashima $^{13} \cdot$ Tomohiko Aihara $^{14} \cdot$ Hirofumi Mukai ${ }^{9} \cdot$ Fumikata Hara ${ }^{15}$

1 Department of Breast and Endocrine Surgery, Okayama University Hospital, 2-5-1 Shikata-cho, Kita-ku,

Okayama 700-8558, Japan

2 Clinical Research Promotion Center, University of Tokyo Hospital, Tokyo, Japan

3 Advanced Cancer Translational Research Institute, Showa University, Tokyo, Japan

4 Breast Disease Center, Asahikawa Medical University Hospital, Hokkaido, Japan

5 Department of Breast Surgery, National Hospital Organization Hokkaido Cancer Center, Hokkaido, Japan

6 Department of Breast Surgery, Teine Keijinkai Hospital, Hokkaido, Japan

7 Department of Breast Surgery, Kansai Medical University Hospital, Osaka, Japan

8 Department of Breast Surgery, Niigata City General Hospital, Niigata, Japan
9 Department of Medical Oncology, National Cancer Center Hospital East, Chiba, Japan

10 Department of Breast Surgery, Hirosaki Municipal Hospital, Aomori, Japan

11 Department of Breast Surgery, Japanese Red Cross Saitama Hospital, Saitama, Japan

12 Department of Medical Oncology, Faculty of Medicine, Kindai University, Osaka, Japan

13 Department of Breast and Endocrine Surgery, Osaka City University Graduate School of Medicine, Osaka, Japan

14 Breast Center, Aihara Hospital, Osaka, Japan

15 Breast Oncology Center, Cancer Institute Hospital of Japanese Foundation for Cancer Research, Tokyo, Japan 